\title{
RUIDOS DA FÉ: ESTRATÉGIAS PARA REDUÇÃO DOS ASPECTOS AMBIENTAIS RESPONSÁVEIS PELA POLUIÇÃO SONORA DE UMA IGREJA EVANGÉLICA EM NATAL/RN.
}

\author{
Fabio Ribeiro de Lima \\ Arquiteto e Urbanista - UFRN \\ Estudante do Curso de Especialização em Gestão Ambiental - IFRN \\ E-mail: fabiorarq@yahoo.com.br
}

\begin{abstract}
Nubelia Moreira da Silva
Licenciada e Bacharel em Geografia. Especialista em Metodologia do Ensino de Geografia. Mestre em Desenvolvimento e Meio Ambiente. Professora do Instituto Federal de Educação, Ciência e Tecnologia do Rio Grande do Norte - IFRN.

E-mail: nubelia@cefetrn.br
\end{abstract}

\section{RESUMO}

A poluição sonora é um dos tipos de poluição do ar mais presente nos aglomerados urbanos. O ruído, de uma forma geral, causa diversos efeitos nocivos aos indivíduos e sua manifestação ocorre tanto nas esferas física, psicológica e social interferindo diretamente na comunicação estabelecida entre eles. Um dos veículos de propagação desse tipo de poluição são os templos evangélicos que em sua maioria não possuem nenhum tipo de preparação acústica para a realização das suas atividades. Com o objetivo maior de criar estratégias para redução dos aspectos ambientais responsáveis pela poluição sonora provocada por esses templos, foram realizadas medições acústicas internas e externas na Igreja Nova Aliança do Brasil, uma igreja localizada em um bairro predominantemente residencial da Cidade do Natal/RN e que apresenta uma série de deficiências relacionadas à problemática em estudo. Dessa forma, para alcançar o objetivo exposto anteriormente foi necessário identificar o comportamento acústico no interior do templo; mensurar a quantidade de ruídos que a igreja gerava no momento de seus cultos; identificar as implicações que os ruídos gerados no templo podem causar no entorno da edificação e, por fim, fornecer subsídios para o tratamento dos aspectos ambientais causadores da poluição sonora urbana. Para a obtenção das informações acima referidas foi necessária a utilização de dois softwares de simulação acústica, a saber, o Reverb e o Aurora, os quais alimentados pelas informações coletadas in loco, como por exemplo, dimensões da edificação, materiais de acabamento das superfícies, tempo de reverberação do som e outros, forneceram dados que comprovaram a necessidade urgente de um tratamento acústico do templo em análise. Além disso, as medições internas e externas realizadas com decibelímetro na edificação no momento de realização do culto complementaram as informações dadas pelos softwares, além de servirem como respaldo para a compreensão da urgente necessidade de isolamento acústico desse e de tantos outros ambientes críticos acusticamente. Como resultado deste trabalho espera-se contribuir para que os gestores tenham subsídios na aplicação de princípios da gestão ambiental urbana no que se refere aos aspectos da poluição sonora e colocar à disposição dos lideres das comunidades religiosas o conhecimento de técnicas simples, eficientes e de baixo custo que possam ajudar a melhorar a qualidade de vida nos centros urbanos, especialmente dos residentes das proximidades dos templos evangélicos e seus freqüentadores.

PALAVRAS-CHAVE: Poluição Sonora, Aspectos Ambientais, Impactos Ambientais, Igrejas Evangélicas e Acústica Arquitetônica. 


\title{
NOISE OF FAITH: STRATEGIES TO REDUCE THE ENVIRONMENTAL ASPECTS RESPONSIBLE FOR THE SOUND POLUTTION FROM AN EVANGELICAL CHURCH IN NATAL/RN.
}

\begin{abstract}
The noise pollution is one of the most violent kinds of pollution in the urban crowds. Noise, in general, causes the worst consequences harmful to human kind and its spread occurs not only in the physical, psychological and social spheres interfering directly in the communication stabilities among them. Examples of this kind of pollution are the evangelical temples that have no acoustic infrastructure of any kind to held their activities. Having in mind the idea of raising strategies to reduce the environmental aspects responsible for the noise pollution provoked by those temples, acoustic measures were in the interior as well as in the outside of the Igreja Nova Aliança do Brasil, a church located in district that is predominantly a residencial area in the city of Natal, RN that shows a lot of defects related to the problem studied thies, to identify the objective proposed before it was necessary to detect the acoustic problem in the inside of the temple; measuring how much noise the church caused at the moment the cults were held; identify the implications that the noise made can cause around the building and finally subsidize the treatment of the environmental aspects brought about the urban noise pollution. In order to get this information mentioned it was necessary to use two softwares of acoustic simulation, i.e., the Reverb and the Aurora, which wore fed with local information, edification dimensions, materials of surface finish, duration of sound spread and others gave the facts to prove the urgent necessity of the acoustic treatment of the temple analyzed. Besides, the interior and the exterior measures taken with decibelimetre in the present building at the moment the cult was held complemented the information given by the softwares, also serving as a support for the awareness of the urgent necessity of the isolation of the building analyzed as well as other buildings conside real inadequate acoustically. As a result of this research paper we to contribute for the application wish principles of urban environmental techniques subsidized by the administrators related to the aspects of noise pollution and give the community religious leaders the knowledge of simple techniques, efficient and at a low cost that can improve the quality of life in the urban centers, especially to the evangelical temples as well as the attendants.
\end{abstract}

KEY-WORDS: Sound Pollution, Environmental Aspects, Environmental Impacts, Evangelicals Churchs and Architectonic Acoustic. 


\section{RUIDOS DA FÉ: ESTRATÉGIAS PARA REDUÇÃO DOS ASPECTOS AMBIENTAIS RESPONSÁVEIS PELA POLUIÇÃO SONORA DE UMA IGREJA EVANGÉLICA EM NATAL/RN.}

\section{INTRODUÇÃO}

$\mathrm{O}$ crescimento das cidades tem gerado impactos ao meio ambiente em proporções nunca antes visto, um deles expresso através da poluição que, segundo Braga et all (2005, p.6), consiste em "[...] alterações indesejáveis nas características físicas, químicas ou biológicas da atmosfera, litosfera e hidrosfera que causa ou pode causar prejuízos a saúde [...]”. Tais alterações interferem sobremaneira no cotidiano de todos aqueles que vivem nos aglomerados urbanos e, são responsáveis pela diminuição da qualidade de vida nesses ambientes.

A poluição atmosférica apresenta-se como um dos mais graves tipos de poluição nos ambientes citadinos. Em suas diversas formas destaca-se a poluição sonora por ser inerente ao crescimento dos aglomerados urbanos, visto que esta se origina, na maioria das vezes, em atividades eminentemente urbanas tais como, tráfego viário, instalações industriais, lazer noturno, cerimônias religiosas dentre outras.

Como resultado destas atividades tem-se o ruído que, de uma forma geral, causa efeitos nocivos aos indivíduos tanto nas esferas física e psicológica quanto social visto que esse interfere diretamente na audição, dificulta a comunicação e causa incômodos de uma forma geral (DERISIO, 2007). De acordo com Lacerda (2005) os ruídos gerados por uma conversa normal de aproximadamente $60 \mathrm{~dB}[\mathrm{~A}]$ é capaz de fazer com que o sistema nervoso vegetativo provoque reações inconscientes, mesmo quando os indivíduos não se sintam incomodados.

Como dito anteriormente, a problemática da poluição sonora é notória nas cidades e uma das fontes de emissão constante de ruídos são os templos evangélicos que se multiplicam no tecido urbano acompanhando seu crescimento. Por isso, pode-se inferir que o controle das emissões sonoras, assim como, a orientação dessas instituições religiosas é um constante desafio para os órgãos públicos brasileiros (prefeituras, departamentos de controle de ruídos, entre outros) que esbarram na própria Constituição Federal que garante livre direto de culto no território Nacional, sendo esse, um dos motivos que influencia na proliferação de templos despreparados acusticamente para a realização de suas atividades e, que são responsáveis pelos sons e ruídos causadores da poluição sonora comum a esses estabelecimentos.

A realidade do quadro religioso brasileiro aponta para a constante mutação que esse vem passando. O País antes predominantemente católico está transformando-se em um lugar onde a diversidade religiosa ganha cada vez mais espaço. Segundo o Instituto Brasileiro de Geografia e Estatística (IBGE) com base no Censo realizado no ano de 2000, o Brasil ainda pode ser considerado um País católico. São 73,6\% de pessoas que se denominam como tal, seguidos apenas pelos evangélicos, $15,4 \%$ da população brasileira. Apesar de esse segmento cristão ser responsável por menos de $1 / 4$ (um quarto) da religião da população brasileira, é certo que existe um crescimento da religião evangélica no Brasil, o que tem acarretado uma série de mudanças, não só religiosas, mas econômicas e sociais visto que a religião antes difundida apenas entre as classes sociais mais pobres encontrou 
atualmente espaço nas demais camadas sociais influenciando e transformando a sociedade brasileira como um todo.

A religião proveniente da Reforma Protestante, ocorrida na Europa Ocidental no século XVI, encontrou no Brasil um campo fértil para o desenvolvimento pleno de suas doutrinas. Por não terem ligação ao Vaticano, os evangélicos, apresentam uma liturgia mais livre que favorece as mais diversas formas de culto com a quantidade de decibéis que lhes apraz, provocando os impactos ambientais tão comuns nas comunidades onde existem templos dessa Religião. Alguns dados fornecidos pelo Ministério de Apoio com Informação $(\mathrm{MAI})^{1}$ referentes à pesquisa realizada no ano de 2001, demonstrou que até aquele ano o número de templos evangélicos na Cidade do Natal chegava a 580 unidades distribuídas nos 36 bairros da Capital Potiguar, o que representa cerca de 16 unidades por bairro.

Portanto, para a realização dessa pesquisa foi selecionada o templo da Igreja Nova Aliança do Brasil. O objeto de estudo dessa pesquisa, está localizada no Bairro de Dix-sept Rosado, uma fração urbana predominantemente residencial. É um templo instalado há pouco mais de cinco anos em uma edificação onde outrora funcionava uma oficina mecânica. Segundo os moradores residentes no entorno, a igreja causa diversos transtornos, principalmente no horário noturno por elevar ao extremo a potência sonora no interior da mesma, quando esses necessitam descansar em suas residências.

De acordo com Sánchez (2006) os impactos ambientais, como os que são associados aos templos evangélicos, são provocados direta ou indiretamente por ações humanas, as quais são denominadas aspectos ambientais pela ABNT NBR ISO 14001:2005. Dessa forma é correto afirmar que os impactos causados pela poluição sonora das igrejas evangélicas, dentre os quais, incômodos aos vizinhos, alterações no sistema nervoso dos freqüentadores dos templos, surdez, entre outros são na verdade o resultado dos aspectos ambientais, ou melhor, das ações humanas responsáveis por essa problemática e, causada na maioria das vezes por elevação da pressão sonora no interior dos recintos, elevado tempo de exposição aos ruídos, equipamentos de som inadequados entre outros.

Tendo em vista que o papel do Gestor Ambiental é o de se posicionar criticamente frente às atuais questões ambientais de forma a contribuir com soluções adequadas que privilegiem o controle dos recursos da natureza (BRUNA et all, 2004), essa pesquisa tem como objetivo apresentar estratégias para a redução dos aspectos ambientais responsáveis pela poluição sonora de uma igreja evangélica da cidade do Natal/RN. Essas soluções, salvaguardando a realidade de cada templo, poderão se estender a outros recintos com a mesma problemática. Como objetivos específicos foram erigidos: reconhecer as características arquitetônicas da edificação que abriga o templo em análise; identificar o comportamento acústico no interior do templo; mensurar a quantidade de ruídos que a igreja gera no momento de seus cultos; identificar as implicações que os ruídos gerados no templo podem causar no entorno da edificação; fornecer subsídios para o tratamento dos aspectos ambientais causadores da problemática em estudo.

Os procedimentos metodológicos utilizados na realização da presente pesquisa foram fundamentalmente três: o primeiro deles consistiu em um levantamento detalhado da edificação, identificando dimensões, formas e materiais utilizados nos revestimentos da mesma para que fosse possível a realização de uma simulação com o software Reverb que

\footnotetext{
${ }^{1}$ Grupo independente que auxilia a igrejas evangélicas brasileiras com dados estatísticos e ferramentas administrativas para a organização das mesmas. (Fonte: www.mai.org.br. Acesso em:27/05/09)
} 
reproduz de forma teórica o comportamento acústico dos ambientes construídos. O segundo consistiu em realizar no interior do templo uma série de medições acústicas com outro software específico para esse tipo de investigação, o Aurora, desenvolvido pelo prof. Ângelo Farina (Itália). Assim, foi possível identificar a qualidade acústica da sala de forma real a partir da Resposta Impulsiva (RI) obtida através do Multi MLS Signal. De posse da simulação teórica e das medições reais realizadas in loco foi possível comparar o Tempo de Reverberação (intervalo de tempo necessário para que a potência sonora diminua $60 \mathrm{~dB}$ [T60 ou T30]) gerado tanto pelo Reverb quanto pelo Aurora. O terceiro procedimento metodológico consistiu na realização de algumas medições com decibelímetro (medidor do nível de pressão sonora), de acordo com a Norma NBR 10151/2000 tanto no interior quanto no exterior da edificação.

Integram ainda os procedimentos metodológicos o levantamento de informações já estabelecidas na literatura específica sobre a temática em baila e a análise de documentos referentes ao tema. A pesquisa de campo foi essencial para o entendimento da realidade aqui abordada, pois, na ocasião, além de todos os levantamentos realizados com vista a conhecer as propriedades e características do templo realizou-se entrevistas informais com lideres religiosos, fieis e a comunidade residente no entorno da igreja com o intuito de conhecer a dimensão da problemática em tela.

Espera-se que os resultados desta pesquisa possam contribuir para que os gestores tenham subsídios na aplicação de princípios da gestão ambiental urbana no que se refere aos aspectos da poluição sonora. Almeja-se colocar à disposição dos lideres das comunidades religiosas o conhecimento de técnicas simples, eficientes e de baixo custo para que estes possam contribuir com a melhoria da qualidade de vida nos centros urbanos, especialmente dos residentes das proximidades dos templos evangélicos, mas também dos fieis que cotidianamente também estão expostos aos aspectos ambientais advindos das atividades praticadas nas igrejas.

\section{RUIDOS DA FÉ: A POLUIÇÃO SONORA ASSOCIADA ÀS IGREJAS EVANGÉLICAS}

De acordo com a World Health Organization apud LACERDA (2005) um dos problemas ambientais que mais afetam a população mundial depois das poluições do ar e da água é a poluição sonora visto que ela está em toda parte, gerando muitas vezes, problemas imperceptíveis aos serem humanos. Além disso, ZANNIN apud LACERDA (2005) aponta para estudos os quais comprovam que quando os indivíduos são submetidos a ruídos constantes, sejam eles no seu ambiente de trabalho ou descanso, esses acabam se adaptando aos mesmos passando a apresentar reações psíquicas como cansaço, nervosismo, entre outras.

Como se sabe, algumas igrejas evangélicas contribuem significativamente com a poluição sonora nos aglomerados urbanos, principalmente quando essas são da linha Pentecostal que segundo Souza (2007) descendem do Movimento Religioso ocorrido nos EUA no inicio do Século XX e que tem como característica de seus cultos o fervor e o "batismo com o Espírito Santo”.

Conforme comprovou Santos (2006) em sua pesquisa sobre a percepção da população a respeito das principais fontes da poluição sonora em Campo Grande-MS, os templos religiosos aparecem comparados às indústrias dessa Cidade com relação ao incômodo gerado aos mesmos. 
De acordo com FERNANDES (2007) não são apenas os vizinhos os principais prejudicados com a poluição sonora provocada por esses recintos, mas principalmente os fiés que se expõem de forma inconseqüente, podendo sofrer lesões tanto psíquicas quanto físicas relacionadas à pressão sonora (volume) no interior dos templos. Segundo levantamentos realizados com decibelímetro (medidor de intensidade sonora) no interior de algumas igrejas evangélicas por este pesquisador no ano de 2007, a maioria dos templos apresentaram níveis entre 95 e $110 \mathrm{~dB}(\mathrm{~A})$. Apenas como parâmetro de comparação vale ressaltar que a intensidade sonora das turbinas de avião e jatos a curta distância chega a $120 \mathrm{~dB}(\mathrm{~A})$, valor este que causa dor e está a apenas $30 \mathrm{~dB}(\mathrm{~A})$ abaixo da intensidade que ocasiona a perda instantânea da audição: 150 dB(A)(CARVALHO, 2006).

No âmbito Legal e Institucional, o Brasil dispõe de alguns dispositivos editados tanto nas instâncias de poder Federal, Estadual e Municipal, além de algumas normas que servem como norteadoras do controle acústico de salas. Dentre os diversos dispositivos Federais destaca-se a Resolução do CONAMA de 08/03/1990, que estabelece diretrizes para a conscientização da população brasileira sobre os prejuízos causados pela poluição sonora.

O estado do Rio Grande do Norte possui a Lei n6621 de 12/07/1994 que dispõe sobre os condicionantes do meio ambiente nesse Estado. Com relação a Igrejas, de um modo geral, essa Lei permite que sejam utilizados instrumentos litúrgicos no exercício de cultos e cerimônias, como sinos, dentro de um horário compreendido entre 7 e 22 horas.

Da mesma forma, o município do Natal possui o Código do Meio Ambiente, ou melhor, a Lei $n^{\circ} 4100$ de 19/06/1992 que dispõe sobre a preservação e manutenção da saúde e da tranqüilidade da população no que se refere ao controle de ruídos no âmbito municipal. Vale destacar nesse instrumento legal, a expressa proibição ao uso de alto-falantes ou congêneres fora dos prédios das igrejas, o que incide diretamente sobre o objeto de estudo dessa pesquisa.

Todas essas Leis, assim como as medições a serem realizadas na presente pesquisa foram respaldadas em duas Normas básicas da Associação Brasileira de Normas Técnicas (ABNT) a NBR 10151/2000 e a NBR 10152/1987, a primeira tem como objetivo instituir parâmetros para a avaliação do nível de ruídos em comunidades, determinando se os mesmos são aceitáveis ou não as atividades humanas. A segunda estabelece os níveis de ruído compatíveis com o conforto acústico em ambientes diversos, deixando claro que para igrejas com atividade de cultos meditativos, o nível aceitável é de 40 a 50 dB.

\section{O BARULHO MORA AO LADO: A PROBLEMÁTICA RELACIONADA À IGREJA NOVA ALIANÇA DO BRASIL}

Como dito anteriormente, para esse estudo de caso foi escolhida a Igreja Evangélica Nova Aliança do Brasil, localizada em uma área predominantemente residencial o que favorece e amplia a problemática dos incômodos causados pela poluição sonora aos vizinhos desse templo conforme pode ser evidenciado na Figura 1. 


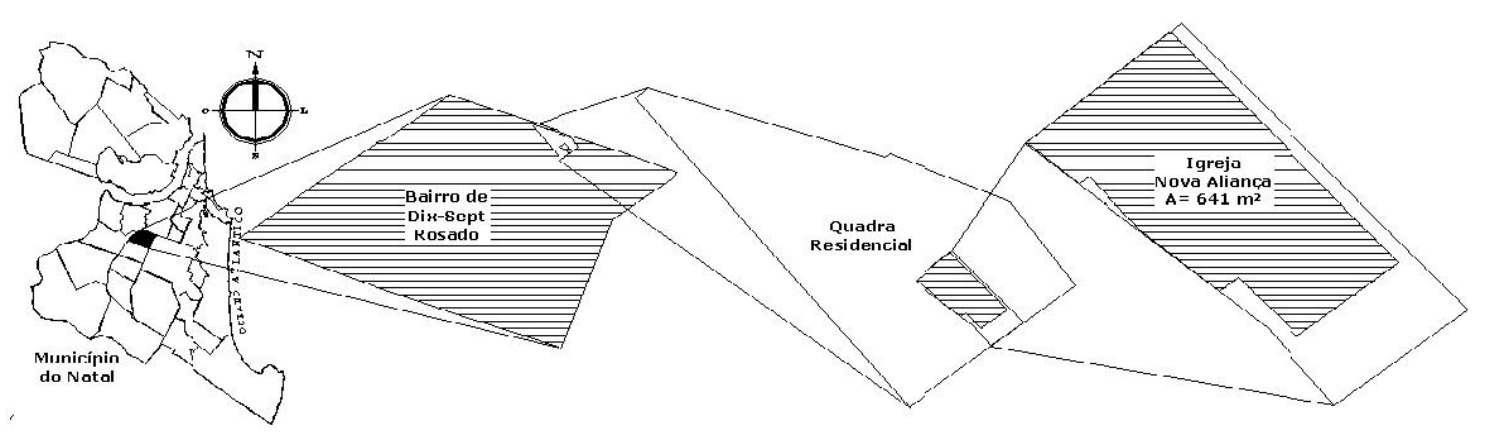

Figura 1. Localização da Igreja Nova Aliança do Brasil (Escala desconhecida).

Fonte: Elaboração do autor a partir de mapa da Companhia de Águas e Esgotos do RN (CAERN) 2002.

De acordo com os vizinhos dessa igreja, o som elevado nos momentos de culto é bastante inconveniente e perturba o sossego de todos. Segundo esses moradores, no momento das celebrações é praticamente impossível realizar atividades simples como ver televisão, ouvir música, dormir, entre outras. Questionados sobre a percepção de alguma alteração no comportamento de membros de suas famílias, os residentes locais dizem que os mais afetados são as crianças que além dos problemas para dormir, visto que essas deveriam recolher-se cedo, apresentam dificuldade de concentração, irritabilidade, ansiedade, inquietude e outras patologias que interferem na tranqüilidade de toda a família. Os adultos questionados queixam-se do som alto alegando que não conseguem descansar no lugar apropriado para isso, isto é, as suas casas. O resultado desse quadro é sempre o mesmo: pessoas agitadas e mais susceptíveis a doenças como aquelas relacionadas por FERNANDES (2007).

Os lideres dessa igreja tem consciência do problema, porém defendem-se alegando que o espaço no interior da igreja é grande e a única forma de alcançar todos os fiés é aumentando a potência sonora de seus equipamentos de som. Com relação a estes se sentirem incomodados durante os eventos, devida à elevada potência sonora no interior da edificação, tanto os líderes quanto os fiés são unânimes em dizer que já estão acostumados e até preferem que essa seja mantida, pois o som elevado os ajuda a concentrarem-se naquilo que esta sendo realizado no culto.

A igreja em análise abrigou outrora uma oficina mecânica, conforme atestaram a visita in loco e a entrevista com os representantes da mesma. Com relação ao uso atual predominante, destaca-se a atividade de culto semanal e dominical, com a ministração da palavra falada e, principalmente, da música (bandas e coral), todas elas auxiliadas por equipamento de som distribuído pela nave da igreja. Além disso, a igreja também realiza encontros informais de seus membros em suas dependências dentre outras atividades.

Acusticamente, a Igreja Nova Aliança do Brasil apresenta características peculiares a sua forma, sendo assim, para que seja possível se compreender como o som se comporta dentro desse ambiente é necessário conhecer elementos básicos da edificação como volume, materiais que compõe as superfícies, dimensões das superfícies em contato com o som, localização, entre outros, por isso, é correto afirmar que o som apresentará comportamento distinto que dependerá do ambiente onde este for emitido. No caso da igreja em análise, esta possui uma planta em forma retangular, com área aproximada de $641 \mathrm{~m}^{2}$ e pé direito de $7 \mathrm{~m}$ a edificação perfaz um volume de aproximadamente $3815 \mathrm{~m}^{3}$, e tem como programa de necessidades o altar e platéia, além de salas auxiliares que não são utilizadas para os 
cultos. O acesso principal da edificação se dá pela porta localizada na parede frontal da mesma, já o acesso alternativo fica localizado na parede lateral esquerda dessa (Figuras 02 e 03).

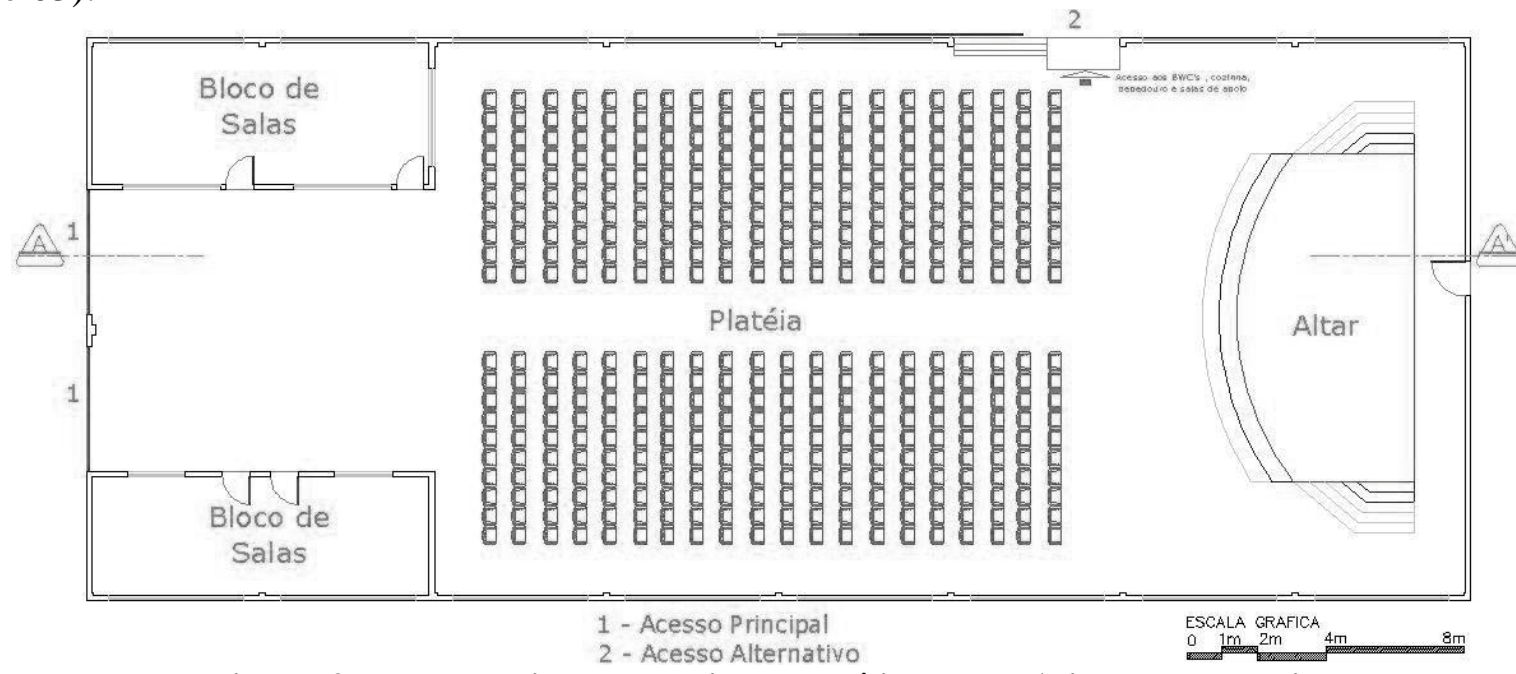

Figura 2: Planta Baixa da Igreja Evangélica Nova Aliança do Brasil.

Fonte: Levantamento in loco pelo autor.

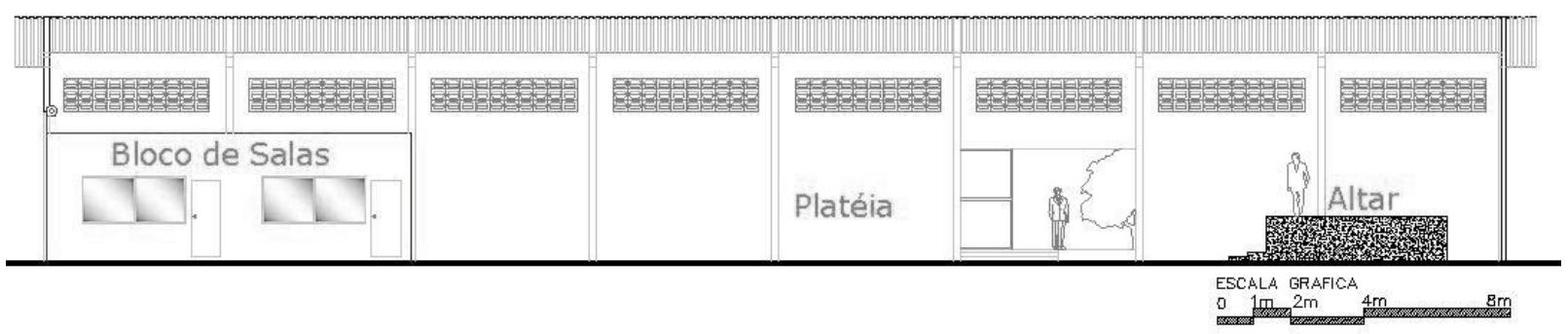

Figura 3: Corte Longitudinal A-A’ da Igreja Evangélica Nova Aliança do Brasil.

Fonte: Levantamento in loco pelo autor.

O altar possui piso elevado com acesso por escadas laterais, onde por trás existem algumas faixas de tecidos tencionados, além disso, ele é revestido por carpete. Tanto a platéia, quanto o restante da edificação possui piso plano cimentado e pintado. A vedação lateral é constituída por paredes de alvenaria rebocadas e pintadas, com elementos vazados (cobogós) em todo o trecho superior da mesma. Os acessos possuem portas de rolo e de correr metálicas, as demais esquadrias são de madeira e vidro. Com relação ao teto, podese dizer que este, com caimento em duas águas, é composto por telhas de fibrocimento. $\mathrm{O}$ mobiliário é formado, basicamente, pelas cadeiras plásticas da platéia e pelos instrumentos musicais sobre o altar.

\section{MEDIÇÕES DOS PARÂMETROS ACÚSTICOS}

A identificação dos aspectos ambientais responsáveis pela poluição sonora dessa igreja, pressupôs algumas medições acústicas no interior, assim como no exterior da mesma para mensurar a poluição gerada pelas atividades desenvolvidas nesse recinto. Uma das formas de se identificar esses aspectos é através da medição de alguns parâmetros objetivos de qualidade acústica em salas reais, a partir da Resposta Impulsiva (RI). Conforme dito anteriormente, para a realização dessas medições foi utilizado o software Aurora, o qual fora desenvolvido pelo prof. Ângelo Farina, obtendo com o mesmo a RI através do sinal 
maximum length sequence (MSL) emitido pelo próprio programa. Dentre os muitos parâmetros sonoros fornecidos por esse software, foram analisados apenas quatro, devido serem esses os parâmetros que melhor avaliam o tipo de uso em um ambiente como esse que utiliza corriqueiramente a palavra falada e a música. Assim foram analisados os seguintes parâmetros: Tempo de Reverberação (T30), Early Decay Time (EDT) ${ }^{2}$, Definição (D50) ${ }^{3}$ e Clareza (C80) ${ }^{4}$.

Com o equipamento de som da própria igreja foi emitido este sinal numa intensidade média de $95 \mathrm{~dB}$, mesurada pelo próprio programa. Os resultados foram analisados levandose em consideração três bandas de freqüências distintas, ou seja, 125, 500 e $2000 \mathrm{~Hz}$, para que fosse possível a caracterização do comportamento do som em freqüências baixas, médias e altas, e assim poder direcionar as soluções mais adequadas a esse tipo de edificação. Os equipamentos portáteis utilizados para a realização das medições foram: Computador portátil Itautec modelo Infoway Note W7645, microfone acoplado ao stereo headphones AIMA M303, tripé para microfone e cabos de conexão.

A medição foi realizada da seguinte maneira: com a igreja vazia, primeiramente posicionou-se o microfone no centro da nave da mesma, no meio da platéia, na altura de $1,5 \mathrm{~m}$, isto porque seria essa a altura média de um ouvinte sentado. Subsequentemente, foi gerado o sinal MSL que foi captado pelo próprio programa num tempo médio de um minuto.

Após a medição, todos os dados obtidos foram salvos no aplicativo Excel, depois tratados e analisados de forma a fornecer as informações referentes aos parâmetros acústicos almejados pela referida pesquisa. Os quais podem ser observados na tabela a seguir:

\section{Tabela 1: Medição de parâmetros acústicos na Igreja Nova Aliança do Brasil com o} Software Aurora

\begin{tabular}{|c|c|c|c|c|}
\hline \multirow{2}{*}{$\begin{array}{l}\text { IG. NOVA } \\
\text { ALIANÇA }\end{array}$} & \multirow{3}{*}{$\begin{array}{c}\text { Parâmetros } \\
1 \\
\end{array}$} & \multicolumn{3}{|c|}{ Freqüências [Hz] } \\
\hline & & 125 & 500 & 2000 \\
\hline T30 [s] & & 1,36 & 1,37 & 1,05 \\
\hline EDT [s] & 1 & 1,20 & 1,87 & 1,96 \\
\hline D50 [\%] & 70 & 14,05 & 52,99 & 38,82 \\
\hline $\mathrm{C} 80 \quad[\mathrm{~dB}]$ & -3 a 0 & $-5,80$ & 1,02 & $-0,16$ \\
\hline
\end{tabular}

Conforme a Tabela 1 existem vários problemas acústicos na igreja analisada. O T30 apresentou-se, em todas as freqüências, acima do parâmetro estabelecido para o tipo de uso da edificação, mesmo assim, ainda é um valor que está longe da realidade, pois pela própria configuração volumétrica da sala que possui pé-direito elevado e diversas superfícies refletoras o que faz com que esse se torne um ambiente muito reverberante, realidade essa refletida no EDT e nos demais parâmetros acústicos. Com relação ao C80,

\footnotetext{
${ }^{2}$ É o tempo necessário para que a curva de decaimento do som caia os primeiros 10 dB do T60. Ao EDT associa-se a sensação de reverberação, ou seja, de prolongamento do som.

${ }^{3}$ É um índice baseado nas reflexões sonoras que atingem o ouvinte nos primeiros 50ms e que reforçam o som direto.

${ }^{4}$ Semelhante à Definição (D50), este índice considera como “reflexões úteis” aquelas que atingem o ouvinte nos primeiros $80 \mathrm{~ms}$.
} 
apenas em freqüências mais elevadas ele apresenta-se dentro do limite, nas demais isto não acontece.

Apesar da incoerência de alguns parâmetros apresentados por este software é possível se ter a idéia da péssima qualidade acústica encontrada neste templo, embora seus organizadores esforcem-se para introduzir de forma intuitiva superfícies absorventes de som, como cortinas, carpetes, dentre outros, esses não tem sido suficientes, pois não interferem de forma significativa no comportamento do som dentro de um ambiente com essas dimensões. Além disso, não há uma preocupação desses em solicitar um planejamento adequado que vise à solução de todos esses problemas nessas edificações, o que demonstra o pensamento da maioria das denominações evangélicas de Natal.

No que se refere à área da Igreja Nova Aliança do Brasil que é utilizada como auditório de múltiplo uso, esta apresenta volume de aproximadamente $3.815 \mathrm{~m}^{3}$, com tempo de reverberação ótimo estimado de 1,3s. Os materiais empregados nas superfícies internas, guardando as devidas adaptações provocadas pela limitação do banco de dados do referido software, podem ser assim descritas: Paredes e pisos de alvenaria pintada; altar revestido com carpete simples; elementos vazados (cobogós) nas extremidades superiores das paredes laterais direita e esquerda, considerados como sendo $30 \%$ absorventes; teto em telhas de fibrocimento; esquadrias de vidro e porta de metal com $20 \%$ de absorção; portas de madeira que absorvem $40 \%$ do som; cortinas de malha tencionadas por trás do altar que absorvem $30 \%$ do som que incide sobre a mesma; devido a falta de um material capaz de substituir as cadeiras plásticas da platéia, utilizou-se o índice da platéia com 400 pessoas sentadas (Figura 3).

\begin{tabular}{|llr|}
\hline Superficie & Material de acabamento & Área $\left(\mathrm{m}^{2}\right)$ \\
Paredes & Alvenaria pintada ou não (De Marco) & 453,9 \\
Piso platéia & Alvenaria pintada ou não (De Marco) & 500,8 \\
Altar & Carpete simples, forrado & 72,1 \\
Elementos & $30 \%$ absorvente & 57,6 \\
vazados & & 649,6 \\
Cobertura & telha de fibrocimento & 17,2 \\
Esquadrias de & $20 \%$ absorvente & 504,0 \\
vidro & & 2,1 \\
Portas de & $40 \%$ absorvente & 39,8 \\
madeira & $20 \%$ absorvente & 2297,1 \\
Porta de metal & Cortinas & $30 \%$ absorvente \\
Area Total & & \\
\hline
\end{tabular}

Figura 3: Lista de superfícies encontradas na Igreja Nova Aliança do Brasil.

Fonte: Levantamento in loco realizado pelo autor e lançado no software Reverb.

A inserção das informações referentes às superfícies internas desse recinto no Software Reverb para fins de análise, geraram os valores descritos nas Figuras 4 e 5.

\begin{tabular}{|c|c|c|c|c|c|c|c|}
\hline & freqi & ência c & entral p & banda & de oita & $\mathrm{a}[\mathrm{Hz}]$ & \\
\hline & 125 & 250 & 500 & 1000 & 2000 & 4000 & NRC \\
\hline Area de Absorção Equivalente [ $\left(\mathrm{r}^{2}\right]$ & 325,9 & 404,0 & 467.6 & 491,2 & 502,4 & 503,9 & 895,6 \\
\hline Tempo de Reverberação Ótimo (s) & 1.3 & 1,3 & 1,3 & 1.3 & 1.3 & 1,3 & 1,3 \\
\hline Tempo de reverberação calculado [s] & 1.9 & 1.5 & 1,3 & 1,2 & 1,2 & 1,2 & 0.7 \\
\hline po de Reverberação calculado [absorção corrigida pela umidade do ar) (s) & 1.9 & 1,5 & 1,3 & 1,2 & 1,1 & 1,0 & \\
\hline
\end{tabular}

Figura 4: Simulação do desempenho acústico na Igreja Nova Aliança do Brasil. Fonte: Levantamento in loco realizado pelo autor e lançado no software Reverb. 


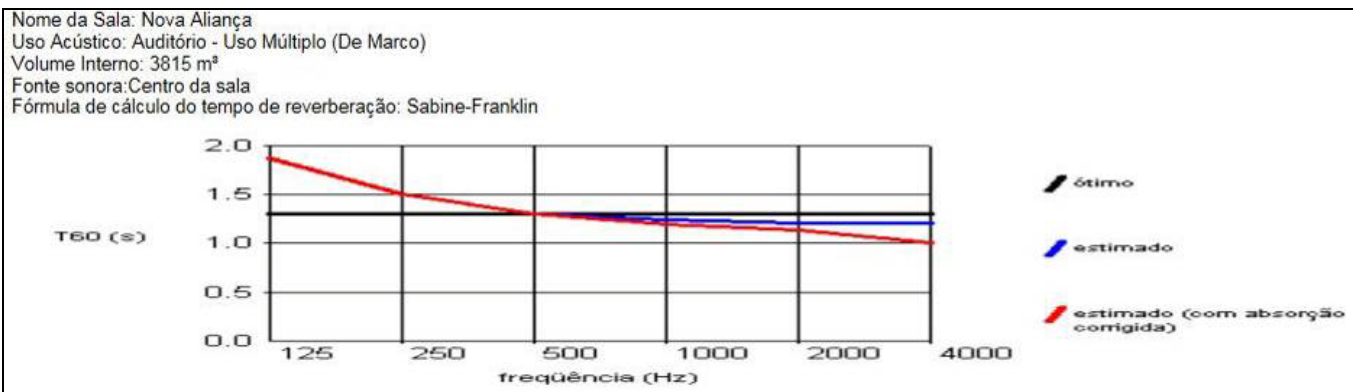

Figura 5: Caracterização e Gráfico T60 x Freqüência para a Igreja Nova Aliança do Brasil Fonte: Levantamento in loco realizado pelo autor e lançado no software Reverb.

Apesar do volume e das superfícies encontradas na igreja acima, a simulação demonstrou que para as freqüências de média a baixa o tempo de reverberação está acima do estabelecido para este tipo de atividade, ao contrario das médias e altas que estão abaixo, isto implica em dizer que neste ambiente, segundo o software, os sons agudos são rapidamente absorvidos pelo ambiente, enquanto que os graves prolongam-se mais.

Segundo as simulações do Reverb vistas anteriormente, o Tempo de Reverberação está superior ao tempo ótimo estabelecido pelo programa, principalmente para as freqüências mais baixas, isso porque são essas as freqüências mais difíceis de serem absorvidas pelas superfícies, diferentemente das mais altas, as quais são absorvidas rapidamente pelos materiais e elementos presentes nesses espaços. Isso comprova que essa sala pode ser considerada como "viva" ${ }^{5}$, de difícil inteligibilidade", onde a palavra falada é de difícil compreensão sem a utilização de equipamentos de som. Tal resultado apenas comprova o que foi verificado com o programa Aurora, onde superfícies refletoras aliadas ao grande volume da sala acaba agravando a problemática ora apresentada, conforme comparação entre os tempos de reverberação encontrados em ambos os softwares (Tabela 2 e a Figura 6):

Tabela 2: Comparação entre o Tempo de Reverberação encontrado pelo Aurora e simulado pelo Reverb

\begin{tabular}{|c|r|r|r|}
\hline \multicolumn{3}{|c|}{ Tempo de Reverberação Aurora x } \\
Reverb \\
\hline \multirow{3}{*}{$\begin{array}{c}\text { Igreja Nova } \\
\text { Aliança do Brasil }\end{array}$} & Freq. (Hz) & Aurora & Reverb \\
\cline { 2 - 4 } & 125 & 1,36 & 1,9 \\
\cline { 2 - 4 } & 2000 & 1,37 & 1,3 \\
\hline
\end{tabular}

Fonte: Levantamento in loco realizado pelo autor e lançado nos softwares Aurora e Reverb.

Como é possível perceber pela comparação anterior, as freqüências baixas são as mais problemáticas, apesar dos contrastes ocorridos entre os dois softwares, ou seja, enquanto o Aurora registrou tempos de reverberação para essas freqüências abaixo do tempo ótimo, o Reverb os simulou como muito superior a esse. No entanto, como já fora dito anteriormente, a experiência obtida nessas salas comprova que o Reverb aproxima-se mais da realidade, além disso, os outros índices do próprio Aurora (EDT, D50, C80) comprovam algumas alterações para essas freqüências, por isso, pode-se afirmar que um

\footnotetext{
${ }^{5}$ Reverberação em excesso.

6 “É a menor ou maior capacidade de reconhecimento da palavra falada, num determinado local." (SILVA, 2005, p.147)
} 
dos principais problemas das igrejas evangélicas está associado ao controle e acondicionamento dessas salas para as baixas freqüências, as quais espalham-se principalmente pela estrutura das edificações.

Figura 6: Caracterização e Gráfico T60 x Freqüência para a Igreja Nova Aliança do Brasil Fonte: Levantamento in loco realizado pelo autor e lançado no software Reverb

\subsection{Avaliação de ruído produzido pela Igreja Nova Aliança do Brasil}

Para a avaliação de ruído produzido por essa igreja foram instalados 7 pontos de medição nos locais indicados na Figura 7 os quais apresentaram os níveis sonoros que constam na Tabela 3:

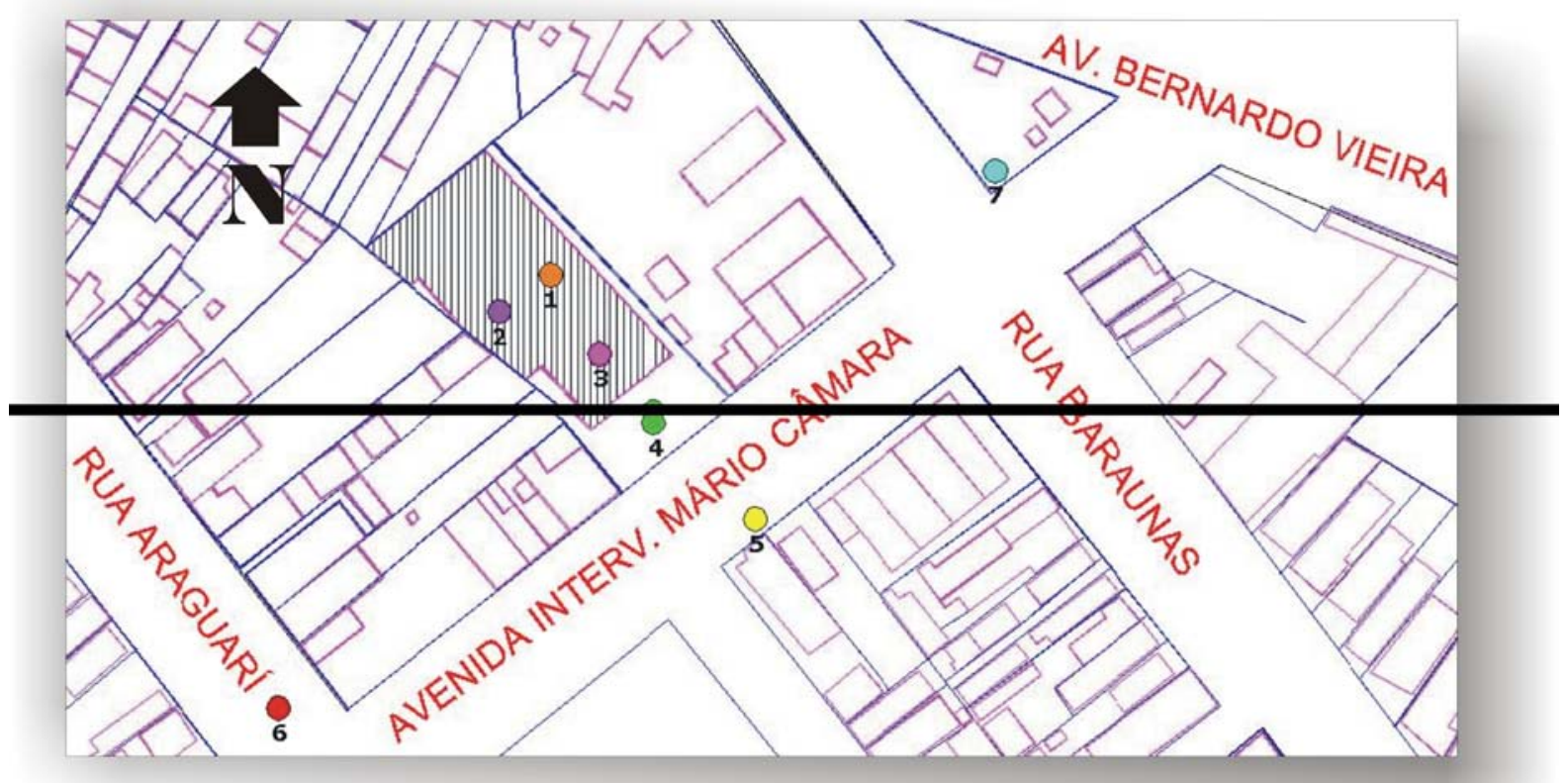

Figura 7: Localização da Igreja Nova Aliança e dos pontos de medição de ruído Fonte: Mapa elaborado pelo autor a partir do mapa da CAERN (2002) 
Tabela 3: Resultado da medição da intensidade sonora - Igreja Nova Aliança

Medição da intensidade Sonora em campo - Igreja Nova Aliança $[\mathrm{dB}(\mathrm{A})]$

\begin{tabular}{|c|c|c|c|c|c|}
\hline \multirow{2}{*}{ Pontos } & \multirow{2}{*}{ Caracterização } & \multicolumn{2}{|c|}{ Antes do Culto } & \multicolumn{2}{|c|}{ Durante o Culto } \\
\hline & & Minimo & Máximo & Minimo & Máximo \\
\hline P1 & $\begin{array}{l}\text { Interior da Igreja, } \\
\text { no corredor direito } \\
\text { da platéia. }\end{array}$ & 66,0 & 80,8 & 91,6 & 102,4 \\
\hline P2 & $\begin{array}{l}\text { Interior da igreja, } \\
\text { no corredor } \\
\text { esquerdo da } \\
\text { platéia. }\end{array}$ & 56,3 & 79,9 & 92,6 & 102,7 \\
\hline P3 & $\begin{array}{l}\text { Fundo da igreja, } \\
\text { próximo a entrada } \\
\text { principal. }\end{array}$ & 62,5 & 69,4 & 95,4 & 104,6 \\
\hline P4 & $\begin{array}{l}\text { Frente da Igreja, } \\
\text { na calçada. }\end{array}$ & 65,2 & 80,1 & 81,3 & 94,5 \\
\hline P5 & $\begin{array}{c}\text { Frente da Igreja, } \\
\text { do outro lado da } \\
\text { rua. }\end{array}$ & 59,1 & 76,1 & 78,3 & 84,9 \\
\hline P6 & $\begin{array}{c}\text { Esquina entre a } \\
\text { Rua Araguari e Av. } \\
\text { Interv. Mário } \\
\text { Câmara. }\end{array}$ & 64,4 & 69,3 & 66,5 & 69,3 \\
\hline P7 & $\begin{array}{c}\text { Esquina entre a R. } \\
\text { Baraúna e Av. } \\
\text { Interv. Mário } \\
\text { Câmara. }\end{array}$ & 61,7 & 79,7 & 63,8 & 75,5 \\
\hline
\end{tabular}

Fonte: Levantamento in loco realizado pelo autor.

Partindo dos níveis de ruído estabelecidos pela Norma (NBR 10151/2000) a área onde essa igreja está instalada pode ser considerada como sendo uma área mista, predominantemente residencial, por isso os níveis de critério para avaliação de ruídos em ambientes externos estabelece como padrão $55 \mathrm{~dB}(\mathrm{~A})$ durante o dia e $50 \mathrm{~dB}(\mathrm{~A})$ a noite. Porém como se pode ver, principalmente nas medições realizadas nos pontos 6 e 7, o ruído de fundo já ultrapassa o estabelecido pela norma, pois nessa área estão presentes alguns bares, paradas de ônibus, oficinas mecânicas e comércios em geral. Dentro da igreja o ruído de fundo, também é superior ao estabelecido na norma, é provocado por algumas pessoas conversando, porém, como a igreja é bastante reverberante, esse nível é elevado.

No momento da realização do culto os resultados foram os seguintes: os quatro primeiros pontos, por se localizarem mais próximo a fonte de emissão de som, apresentam os maiores valores de intensidade sonora. Assim, os níveis sonoros dentro do ambiente de culto no momento da execução da música chegam a níveis que comparados com outros tipos de ruído, podem causar estresse, dores de cabeça e outras patologias em indivíduos submetidos a exposição prolongada. Segundo BISTAFA (2006) um ambiente com essa pressão sonora pode ser classificado como muito barulhento e os ruídos podem ser comparados àqueles gerados por uma britadeira, bem como por um metrô. No P5 a 
intensidade do som ainda é elevada, o que provoca incomodo ao vizinho que se encontra ali instalado. Diferentemente dos pontos P6 e P7, os quais se mantiveram com seus índices sem muita variação.

De forma geral, os níveis sonoros encontrados no interior dessa igreja estão superiores ao tipo de atividade desenvolvida na mesma, e isto é provocado pela necessidade que o ambiente apresenta de elevar a pressão sonora interna para que o som seja compreendido por todos os ouvintes, o que demonstra a urgente necessidade do isolamento e condicionamento acústico do templo.

\section{ESTRATÉGIAS PARA REDUÇÃO DOS ASPECTOS AMBIENTAIS DA POLUIÇÃO SONORA OCASIONADA PELA IGREJA NOVA ALIANÇA DO BRASIL}

Como é possível perceber, os aspectos ambientais responsáveis pela poluição sonora da Igreja Nova Aliança estão relacionados principalmente a deficiência acústica encontrada nessa. Por este motivo, as estratégias propostas para essa edificação darão enfoque ao isolamento e acondicionamento acústico de forma que se evitem os danos causados por este tipo de poluição.

Para que seja possível interferir acusticamente numa edificação é necessária a compreensão de que existe uma diferença entre o isolamento e acondicionamento acústico a qual refletirá nas soluções propostas. Sendo assim, pode-se dizer que o isolamento tem como objetivo não deixar passar som de dentro para fora do ambiente, nem vice-versa, diferentemente do acondicionamento que busca criar uma sonoridade agradável dentro desse, controlando efeitos como a reverberação e ecos, consertando problemas modais e promovendo uma resposta de freqüências adequada ao tipo de utilização. No caso da Igreja em análise as duas formas serão propostas. É importante ressaltar que o objetivo dessas não é de fornecer um projeto acústico executivo para o templo, mas fornecer algumas soluções que poderão ser amadurecidas e aplicadas tanto nessa quanto em outros ambientes com problemas semelhantes.

Os principais aspectos ambientais causadores da constante poluição sonora são provocados, basicamente, pelo grande volume espacial desse ambiente bem como pela inexistência de qualquer tipo de tratamento acústico interno o que faz com que se eleve a pressão sonora a níveis indesejáveis, principalmente para a vizinhança, por essa razão, a primeira atitude a ser tomada é, sem dúvidas, o isolamento acústico.

O confinamento da sala de culto é o mais indicado, visto que, é um espaço com grande volume, porém mal aproveitado. O elevado pé direito, bem como o extenso comprimento da platéia faz com que o som direto seja mal distribuído na sala, assim como aumenta o tempo de reverberação no interior da mesma. Sugere-se então, uma nova geometria no sentido de diminui o pé direito, com rebaixamento de forro, aplicação de material absorvente no fundo da platéia, painéis difusores próximos ao altar e diminuição do espaço vazio atrás desse, que também contribui para o acúmulo de ondas estacionárias ${ }^{7}$ nesse local.

\footnotetext{
${ }^{7}$ É a sobreposição de ondas sonoras de mesma freqüência com sentidos opostos às quais produzem um som fraco e sem qualidade.
} 
Como a liderança da igreja tem a necessidade de criação de outras salas (secretaria, tesouraria, miniauditório) para a mesma, será proposta a inserção desses novos ambientes dentro do grande vão que forma o templo, conforme visto nos esquemas a seguir:

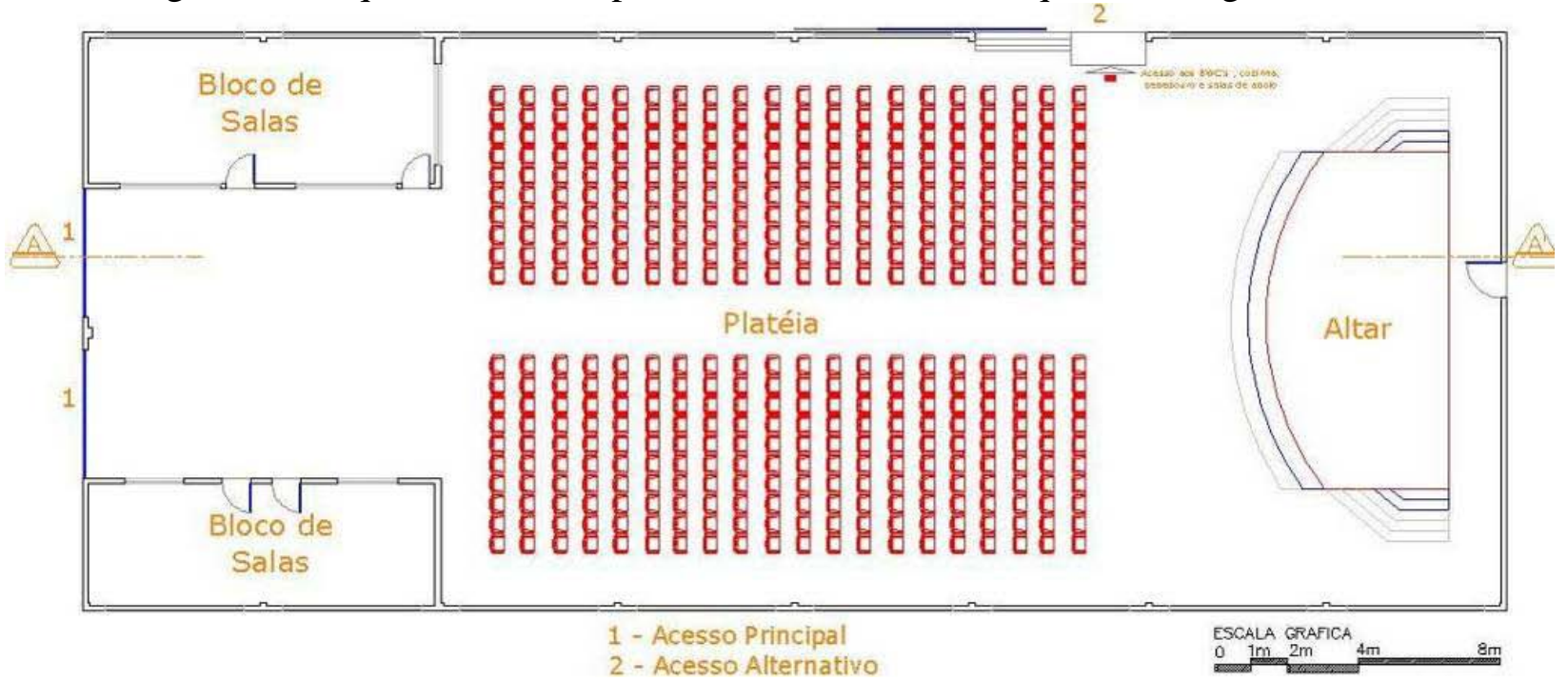

Figura 8: Planta baixa esquemática da Igreja Nova Aliança sem alterações.

Fonte: Levantamento no local pelo autor.

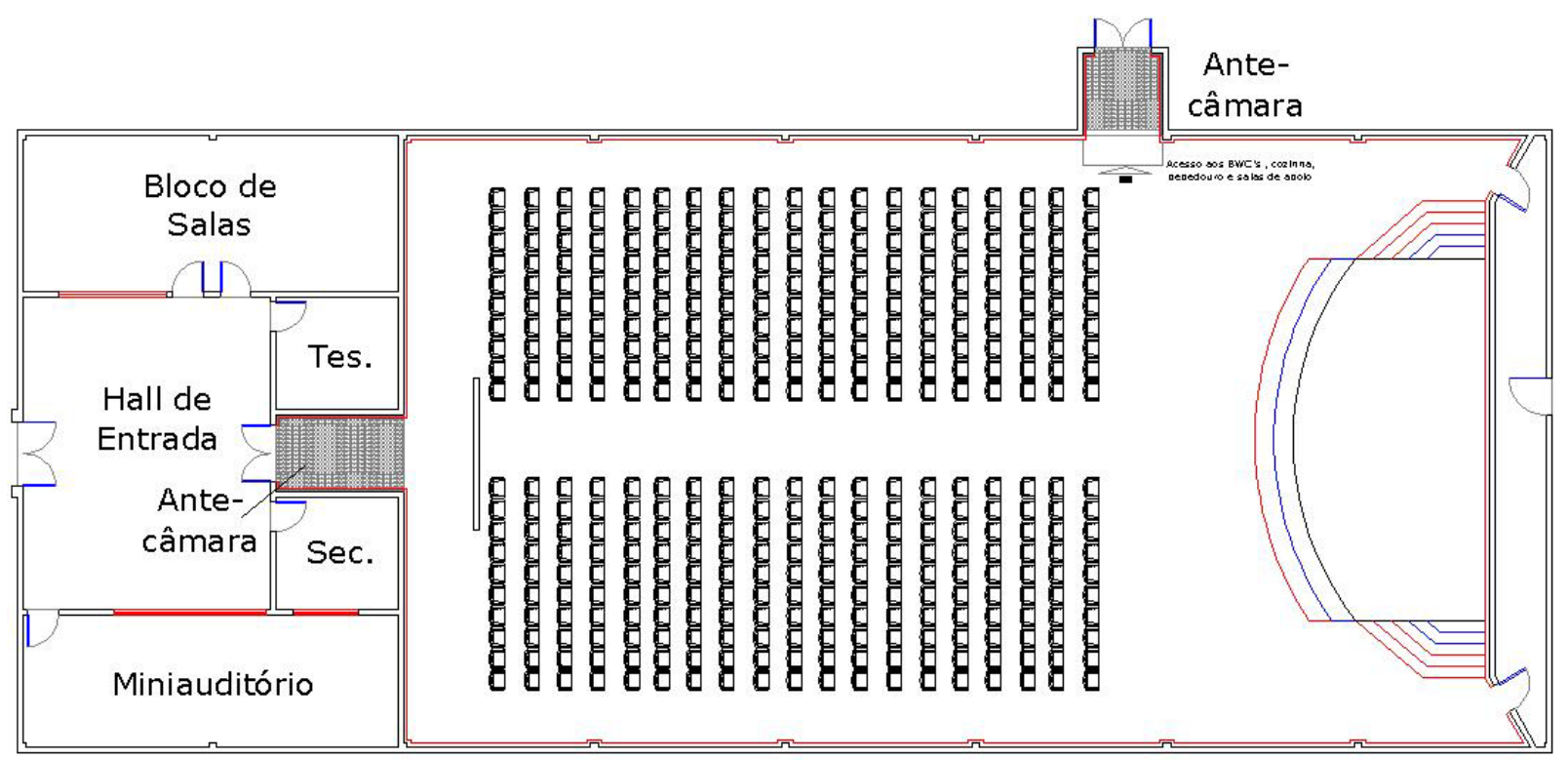

Figura 9: Planta baixa esquemática com intervenções sugeridas para a Igreja Nova Aliança

Fonte: o autor.

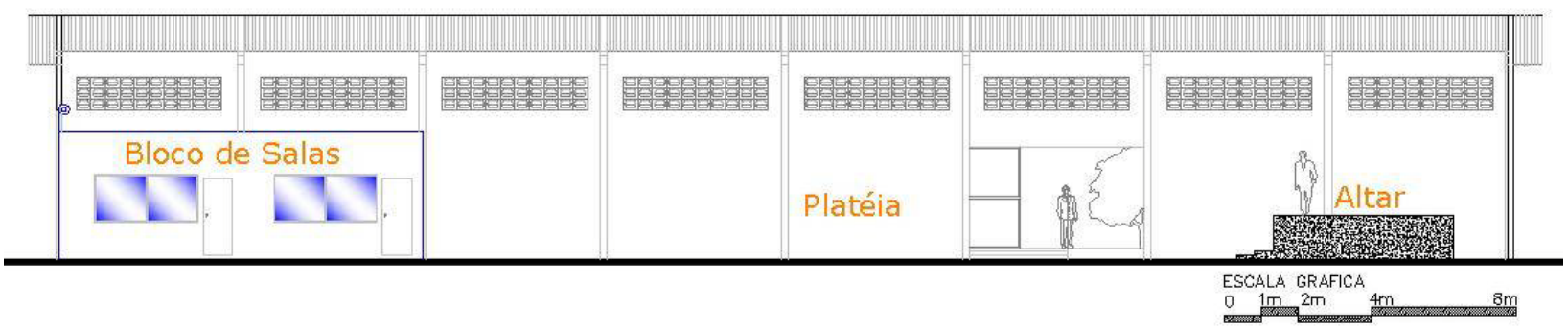

Figura 10: Corte esquemático da Igreja Nova Aliança sem alterações

Fonte: 0 autor 


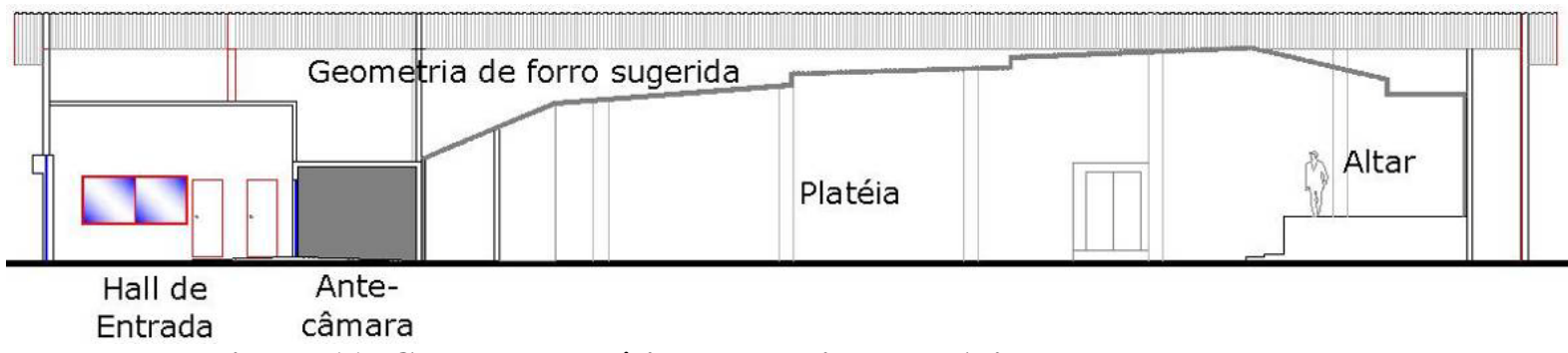

Figura 11: Corte esquemático da Igreja Nova Aliança com alterações

Fonte: o autor

Como se pode ver, as diretrizes indicadas para o isolamento dessa igreja consistem basicamente das seguintes: a) Criação de ante-câmaras revestidas com material poroso, tipo sonex para que o som seja muito absorvido e pouco refletido; b) Portas acústicas para isolamento e confinamento dos ruídos internos e externos; c) Fechamento de todas as aberturas nas paredes da sala de culto; d) Diminuir o paralelismo entre paredes para a redução do eco; e) O material de revestimento interno deverá refletir bem o som na área onde estiver localizado o altar (pinturas, mármores, vernizes, vidros, entre outras), absorver ligeiramente o som que vai para a platéia (pintura fosca granulada, lambris de madeira, tapeçaria e etc.) e absorver totalmente o som direcionado ao fundo da sala (materiais porosos e fibrosos); f) Parede dupla com gesso acartonado e lã de vidro, montantes independentes da parede com calços de neopreme para amenizar as vibrações causadas pelas baixas freqüências; g) Forro com placas de lã de vidro com película de PVC microperfurada, com geometria especifica a qual proporcione distribuição do som uniformemente em toda a platéia; h) Utilização de vegetação entre a fonte e o receptor, pois essa espalha o som incidente sobre ela. i) Devido ao total confinamento dessa sala, é indicada a adoção de ventilação mecânica, tipo ar condicionado.

\section{CONSIDERAÇÕES FINAIS}

Como pôde ser comprovado por esta pesquisa, a problemática ambiental ocasionada pela poluição sonora de templos evangélicos é um fato real e precisa de cuidados especiais. Apenas como informação adicional é importante destacar a pesquisa realizada por Lima (2008), junto as principais entidades evangélicas locais (430 templos) o qual contatou que a maioria delas (mais de 90\%) apresenta problemas relacionados à acústica arquitetônica os quais são provocados, principalmente pela instalação das mesmas em locais impróprios para o seu funcionamento, como por exemplo, em galpões onde outrora funcionaram oficinas mecânicas, supermercados e etc.. Além disso, construções sem planejamento e adaptações de espaços que não vislumbram os aspectos acústicos de acondicionamento dos ambientes também podem ser relacionados como causas da maioria dos problemas com poluição sonora.

A partir dos resultados obtidos com o presente trabalho, infere-se que o ideal seria que essas edificações estivessem locadas em espaços afastados dos centros urbanos, no entanto, isso não ocorre pelo fato das igrejas sempre priorizarem a instalação de suas edificações em locais os mais próximos possíveis de seus freqüentadores, por isso, é que as áreas residenciais são as mais atingidas pelo excesso de ruídos provocados no interior dos templos.

Essa realidade foi comprovada pelo estudo de referência direto realizado com a Igreja Nova Aliança do Brasil que apresentou como um dos aspectos ambientais principais o 
excessivo tempo de reverberação interno, ocasionando baixa inteligibilidade, pouca definição e clareza para a palavra falada, ou seja, ela é uma edificação imprópria para a utilização de um de seus principais usos, as pregações. Além disso, o reflexo dessas condições acústicas é perceptível nas pessoas que residem no entorno desse templo que se mostram bastante irritadas quando questionadas com relação aos impactos sonoros causados pela igreja.

Com relação à Legislação Ambiental existente, pouco se fala sobre o tratamento dos aspectos ambientais encontrados nessas edificações, no máximo, é feito um controle nos horários das emissões sonoras bem como são estabelecidas algumas permissões ou proibições de equipamentos e nada mais, o que acaba por ser insuficiente em determinados casos onde a Legislação não se aplica.

No entanto é importante que os responsáveis pelos templos evangélicos se conscientizem de que não se trata apenas de questões relacionadas exclusivamente a qualidade do meio ambiente, o que já seria um importante motivo, mas principalmente, a saúde das pessoas expostas a essa problemática. Dessa forma torna-se imprescindível a adequação acústica dos espaços de cultos existentes para que tanto os fiés que freqüentam essas edificações quanto à população do seu entorno não sofra com os danos que essa causa.

Por fim, comprova-se que a realidade diagnosticada por esta pesquisa é um problema sério que vai além do limite religioso, esbarrando nas questões sociais e de qualidade de vida tanto para aqueles que freqüentam as reuniões religiosas quanto para seus vizinhos e transeuntes os quais são submetidos, mesmo contra vontade, a essa "agressão sonora". Por isso, a relevância desse trabalho o qual buscou apresentar subsídios técnicos para a conscientização, bem como para o tratamento dos aspectos ambientais responsáveis pela poluição sonora não apenas para uma igreja em especial, mas para todas aquelas que apresentarem problemas semelhantes, sabendo que a mudança do espaço físico só será realidade quando se mudar primeiramente a consciência de que todos têm direito ao culto, contanto que respeitem o espaço do próximo, promovendo assim, a paz.

\section{REFERÊNCIAS BIBLIOGRÁFICAS}

1. ABNT - Associação Brasileira de Normas Técnicas. NBR 6023: Informação e documentação - Referências - Elaboração. Rio de Janeiro, 2002.

2. _ A A Associação Brasileira de Normas Técnicas. NBR 10520: Informação e documentação - Citações em documentos - Apresentação. Rio de Janeiro, 2002.

3. _ Associação Brasileira de Normas Técnicas. NBR 10151: Acústica Avaliação do ruído em áreas habitadas, visando o conforto da comunidade procedimento. Rio de Janeiro, 1999.

4. __ Associação Brasileira de Normas Técnicas. NBR 10152: Níveis de ruído para conforto acústico. Rio de Janeiro, 1987.

5. BISTAFA, Sylvio Reynaldo. Acústica Arquitetônica: Qualidade sonora em salas de audição crítica. Descrição detalhada. (2005) < Disponível em:www.poli.usp.br /p/syvio.bistafa / ACUSARQ/ACUSARQ_CNPQ.pdf > Acesso em: 16Abr. 2008. 
6. BRAGA, Benedito et all. Introdução à Engenharia Ambiental. 2 ed. São Paulo: Pearson Prentice Hall, 2005.

7. BRUNA, Gilda Collet et all. Curso de Gestão Ambiental. Barueri: Manole, 2004.

8. CARVALHO, R. P. Acústica Arquitetônica. Brasília: Thesaurus, 2006.

9. DERISIO, José Carlos. Introdução ao Controle da Poluição Ambiental. $3^{\text {a }}$ Ed. São Paulo: Sigmus Editora, 2007.

10.FERNANDES, Davi. Controle Sonoro. $<$ Disponível em: http://www.musicaeadoracao.com.br/tecnicos/sonorizacao/controle_sonoro.htm> Acesso em: 25 Jan. 2009.

11. LACERDA, Adriana Bender Moreira de et all. Ambiente Urbano e Percepção da Poluição Sonora. Revista Ambiente \& Sociedade, Campinas, v. 3, n. 2, p. 85-91, jul./dez. 2005.

12. LIMA, Fábio Ribeiro de. Decibéis e fé: A questão acústica em igrejas evangélicas de Natal/RN. Trabalho final de graduação. UFRN: 2008.

13. MAI - Ministério de Apoio com Informação. <Disponível em: http://www.mai.org.br> Acesso em: 19 Mai. 2008.

14. PREFEITURA MUNICIPAL DE NATAL. Conheça melhor nossa cidade. Natal, 2003. Disponível em: <http://www.natal.rn.gov.br/semurb/>. Acesso em: $10 \mathrm{dez} .2007$.

15. Plano Diretor de Natal. Lei Complementar nº 082 de 21 de Junho de 2007. Dispõe sobre o Plano Diretor de Natal e dá outras providências. Câmara Municipal, Natal, RN, 21 de set. 2007. Disponível em: <http://www.natal.rn.gov.br/semurb/>. Acesso em: 9 set. 2007

16. SÁNCHEZ, Luis Henrique. Avaliação de Impacto Ambiental: Conceitos e Métodos. São Paulo: Oficina de Textos, 2006.

17. SANTOS, Aloizo Rodrigues dos. Poluição Sonora no perímetro urbano da cidade de Campo Grande - MS. Dissertação de Mestrado. Campo Grande: UNIDERP, 2006. 